\title{
Two Types of Adaptive M'T Environments
}

\author{
Sergei NIRENBUR(: \\ Center for Machine Translation \\ Carnegie Mellon University \\ Pittsburgh, PA, USA \\ David FARWELI. \\ Computing Research Lab \\ New mexico State University \\ Las Cruces, NM, USA
}

\begin{abstract}
ABST'RACI
A number of proposals have come up in recent years for hybridization of MT. Current M' projects - - botl "puse" and hybrid, both predominantly techology-oriented and scientilic (including those comrently funded by NST) are single-engine projects, calpable of one particular type of source text anilysis, one particular method of finding langet language contespondences for source language elements and one prescribed method of generating the target language lext. While such projects can be quite useful, we believe that it is time u make the next step in the design of mathine latuslation systems and to move roward andiptive, multiple-engine systems. We describe fle architecture of an adaptive multi-cngine MT system which uses each of the engines under the circumstances which are most favorable for its success.
\end{abstract}

\section{Multi-Lngine MT Architecture}

Recent years have witnessed a shift in the balance of scientific and lechological efforts in the area of mathine translation. All the latest methodological novellies in this field ate essentially technology-oriented and do not aim at alvancing our knowledge about either basic mechatnisms of text comprehension and production or computer models simulating such mechanisms.

The wo most recently popular technologrical paridigms in machine translation - example-based manslation (EBMT) and statistics-based translation (SIBMT) - require linguistic knowledge only ats an afterthought. While the representatives of the above paradigms are still at the stage of either building toy systems (e.g., Furuse and lida. 1992; MCLean, 1992, Jones, 1992, Mannyama and Walanabe, 1992) or struggling with the natural constraints of approaches that eschew the study of language as such (e.g., Brown et al., 1990), a number of proposals have come up for some hybridization of MT. In some such atpproiches,

\author{
Robert HREIDERKING \\ Center for Machine Translation \\ Cannegie Mellon University \\ pittsburgh, PA, USA \\ Yorick WII KS \\ Department of Computer Science \\ University of Sheflield \\ UK
}

corpus analysis is used for tuning analysis and transfer grammins (e.p., Su and (hing, 1992). In others, a standard transfer-based approitch (T'BMT) is followed using traditional analysis and generation technipues but having a transfer componen based on aligned bilingual corpora (Grishman and Kosakit, lo92). Still others, use statistical information as the source of preference assigmment during tex dismmbignation (e.g., the outline presented in 1.chmam and (31, 1992). Statistical modeling can be lised at some stages of a knowledge-based MT (KBMT) system (sece, e.g., Helmreich, 1)44).

Cument MT' projects - both "pure" and hybrid, both predominamtly techology-orientedand scientilic are single-chrone projects, capable of one paticutar lype of source text analysis, one particulat medhot of tinding target languatge correspondences for source language elements and one prescribed methot of generating the latget language kext. While such projects can be guite useful, we believe that it is time to mate the next step in the design of machine translation systems and to move toward aldaptive, multiple-engine systems.

Pratical MT systems are lypically developed for a parliculat text type (c.g., weather reports, financial news articles, scientific abstracts) and lor a particular end use c.t.. alsimitation or dissemination of information. Special cases, stoch ats thanslating an mpdated version of a previousty transtated rext, abound in the real-world pratice. Gains in output quality and efliciency can he expected if a machine tanshation environnent can be makle to adapt 10 a lask profile. 'Thus, for example, for translating abstracts of scientific articles in order to select just flose that atre of particular interest to a customer, a statistics-based approach might be most appropriate. Fixample-based translation seems to be most promising for translating new versions of previonsly translated docmments. This correspondence between technique, input text type and end use (or output text type) provides lurther molivation for moving towatcd adtaplive, multiple-engine systems.

We perceive two approances to addiplivity in MT: Both presuppose an $\mathrm{M}^{\circ} \mathrm{T}$ environment in which a mumber of MT engines are present - lor instance, one (or more!) each of KBM'T', SBM'T, EBMT' and 'TBM'T engines can 
be used. In one of the approatches all available engines ate "unleashed" on an input text and the final output is assembled from the best text segments, irrespective of which engine produced them. We catl this approach the Best Output Segment (BOS) approach. In another approach a heuristic "dispatcher" decides which of the available engines holds the highest promise for a given input text and then assigns the job to that engine. This is the Dispatcher-Based (DB) approach. The BOS approach involves more processing but allows an a posteriori stlection of the best results. The DB approach saves cycles but relies on heuristic a priori selection of the best output. In this latter case, the quality of the dispatcher module is crucial, but atditionally, the DB approach expects each of the component engines to be of rather high quality, since they would not (as is the case in the BOS approach) be "biiled out" by other engines in case of lailure.

In what follows we hriefly describe our first experinent with the BOS approach and discuss the requirements for the DB approalch.

\section{The Best Output Segment Approach to Adaptivity}

Our BOS approach experiment was cartied out for a Spanish - English translation set-up in the framework of the Pangloss MT project (Pangloss, 1994) and used three MT engines - KBMT, EBM'T, and TBMT.

The KBMT engine we used was the mainline engine of the Pangloss system, a traditional KBMT environment described in some detail in (Pangloss, 1994). It was important for the BOS experiment that this engine generated an internal quality rating for each output segment it produced.

The basic idea of EBMT is simple (cf. Natho, 1984): an input passage $S$ is compared with the source-langulage "side" of a bilingual text archive, where text passiges are stored with their transtations into at langet language for at set of such). The "closest" match, passage $S$ " is selected and the ratnslation of this closest match, the passatge $l^{\prime}$ is accepted as the translation of S. Our EBMT engine used a $100 \mathrm{MB}$ bilingual Spanish - English archive of UN official documents. In preparation for processing, the archive was aligned at the sentence level. The matching of input passages with the Spanish side of the arehive was allowed to be inexact. Penalties were assessed for omitted and extra words, word occurrences in different morphological forms and differences in word order. The English string translating the best Spanish archive candidate was then found in the English sentence aligned with the Spanish sentence in which the best match candidate appeared. A Spanish - English MRD was used in determining tramslattions of individual words inside the candidate segments. A special routine then calculated the expected quality of the resulting translation, which helped at the result integration stage of multi-engine MT system operation. Our
EBMT approach is described in Nirenbutr en al., 1993 and Nirenburg el at., submitsed .

Our transfer system was very simple. It was bated on direct lexical substitution fo English words and phrases for Spanish words and phrase, fortified with morphological analysis and synthesis modules. The process relied on a number of databases - a Spanish - English MRD, the lexicons used by the KBMT engine, a latge set of user-generated bilingual glossaries as well as a gazetteer and a list of proper and organization names. The usergenerated glossaries for our experiment contained aboul 174,000 entries. Glossary entires contained variables to atlow feature matching and indices to link the patts of phrasal entries that transtated one another. For instance, the following glossary entry

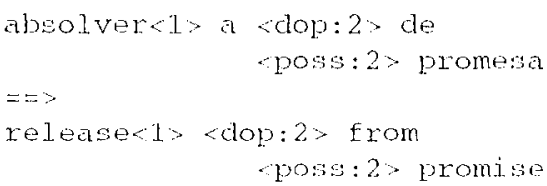

can help to generate such English senteness as

I release you from your promise;

He released me from my promise;

You will be releasing her from

her promise;

etc.

In the rule athove dop stands for "direct object pronoun" and poss for "possessive." Tables of feature correspondences were prepared to make the transtation possible. Note that in many cases Spanisl features and English fealtures were quite different (notably, for verbs). The numbers in angular hrackets are indices which show the morphological synthesizer which word to put in a patrticulat form at generation time. In this experiment we used variables for the lollowing word classes: proper names, such as individual, company and plate names; numbers and the vatrous chasses of pronouns - personal, possessive, reflexive, direct object, indirect object and posiessive absolule.

\subsection{Combining Results}

The crux of the BOS method is combining results from individual engines. A chatrt data structure was used to combine results from the individual engines. Before the translation process, the edges of the chart were made to correspond to individual words in the input. New edges are added to the chart through the operation of the three MT engines labeled with the translation of a segment of the input string and indexed by this segment's heginning and end positions. The KBMT and EBMT engines also carried a quality score for each output element.

After all the engines finished their work it is nees- 
sary to find the sequence of translation candidates whicl a) cover the input string as densely as possible (so that there is a translation for as many source fext clements ats possible); b) use the "best" of the available candidates.

To find the best candidates three heuristics were used -a) internal quality ratings produced by the KBMT and EBMT engines; b) static relative (utality assessment of the particular engines we used and e) the length of the translation segment (the longer, the better). Enlancing the quality of these heuristics and generally finding more sophisticated ways of combining findings of individual engines is the most important direction of improvement or our BOS system.

The chart wealk algoritlm producing the final result of the BOS system used the above heuristies. The algorithm uses dynamic programming to lind the optimal cover (at cover with the best eumulative score), alssuming correct component gnatity scores. It is described in some detitil and illustrated in Nerenburg and Frederking, 1994 and Frederking and Nirenburg, submitted.

\section{The Dispatcher-Based Approach to Adaptivity}

In this approach, a dispatcher module is used to break up the input text into segments and assign each segment 10 one or another of the available MT engines. Among the possible diagnostics for the dispatcher are:

- Type of translation - whether the resull of Iranslation is intended for dissemination or for assimilation whether a complete transtation is needed or an abstract or even a simple categrorizal ion of a texl (e.g.. ats a text that is important enough to be transialed in its contirety).

- Availability of parallel text in a particular domain and on a particular topic. This is the crucial enabling! condition for BBMT and SBMT:

- Amount of ambignity in llae source passage, both in the source language itself and vis-il-vis a target language. The smaller the degree of anbiguily, the more attractive the KBMT approach.

- Size and (quality of available KBMT resources (ontology, lexicons, etc.).

The work on the dispatteher, thus, includes a) evaluating the translation context with rexpect to the four criteria above and b) putting together a decision mechanism which will establish the relative alppropriateness of each of the available engines for treating an input passige in a given context. An additional important parameler in the operation of the dispatcher is determining the most alppropriate size of input passage to be dispatched to an $\mathrm{M}^{\prime} \mathrm{T}$ engine. Since an entire inpul text can be processed by : combination of $\mathrm{MT}$ engines, it is necessaty 10 maximize the expected quatity of oulput over a variety of possible ways of "chunking" the input text for processing. This has some similarity with the chat walk in the BOS approach.

The dispatcher will use an atdditional set ol diagnosties cletermined by the structure of the specific $\mathrm{MT}^{\top}$ engine. The development of these dispalcher hemristics - in oflec words, how lle dispateher is to be trained (see below) -.. is a key point of the proposed research. A probiminary analysis of these specific diagnostic hemristics, ordered by the parlicular engine, follows.

An additional diagnestic henristic for SBMT inspects the frepuency of occumence of each individual input string item in the corpus. The greater the frepuency of the items continined in the text, the greater the likelihood that the SBMT engine will produce grool cuality output.

The above heuristic will also serve the EBMT engine. A heuristic aseful specifically for IBBMT is the amount of overlap of an inpul text with a document alleally in lle source language side of the bilingual archive.

The diagrostics lor the 'T'BM'T' and KBMT' alporoaches' mostly check the coverages of appropriate static knowledpe sourees - - grammans and lexicons.

The diagnostics proposed above valry in cess, both in terms of developing the procedures and in terms of their compulational complexity. Relatively inexpensive atre diagnosties based on recognizing individual forms or paltems in the input (e.g., checking the avatiability of items in a lexicon or a corpus, cluecking llue lengh of segments, checking for local secpuencing patterns of forms). Somtewhat more expensive ane diagnostics batsed on assignment of categories to forms. It is serendipilous, lowever, that the more costly diagnostics are generally related to inilial stages of processing necessary in most engines. This opens a potential lon interleaving the processing by individual engines with the operation of the dispateher.

\section{Filure Work}

The guestions of how fo optimize the combination of evi-

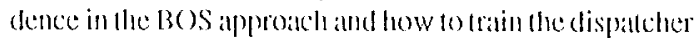
in the DB approach are very close to a key question in modern MT: how an MT system is to be evalluated (even as a small-scale proof of concept). We plan an experimental study to improve the procedure for the combination of evidence from the individual engines in the boS approneth, which will include a comparisen of the results of our system with human judgments and subsequent modification of the system based on this feedback. We also intend toexperiment witl a traning sehedule by which the dispatcher could be trined over text samples, by trying, potentially random assignments of text parts to modules and then seeing which assignment regimes produce the best results. A vatuant on this would be human text "tagring" by intuitions about the text type (where the human lagged it by 
the module type that he considered would be needed; this would be essentially a difficulty rating the text a priori), and again assessing this against system results. As the size of such an experiment can be quite significant, we envisage the use of some form of quasi-attomatic quality scoring for MT of the sort proposed recently by Henry Thompson and his colleagues (e.g., Brew and Thompson, 1994).

\section{References}

Ben Ari, D. M. Rimon and D. Berry. 1988. Translational Ambiguity Rephrased. Proceedings of the Second International Conference on Theoretical and medlodological Issues in Machine Translation. Pittsburgh, June 198x.

Brew, C. and H. Thompson. 1994. Automatic Evaluation of Computer Generated Text: A Progress Report on the TextEval Project. Proceedings of HLT94, Princeton, March.

Brown, P., Cocke, J., Della Pietra, S., Della Pietra, V., Jelinek, F., Mercer, R.L. and Roossin P.S. 1990. A statistical approach to language translation, Computational Linguistics. vol 16,79-85.

Furuse, O and H. lida. 1992. An Example-Based Method for Transfer-Driven Machine Translation. Procedings of TMI-92. Montreal. 139-50.

Grishman, R. and M. Kosaka. 1992. Combining ralionalist and empiricist approaches 10 machine translation. Proceedings of TMI-92. Montreal. 263-74

Isabelle, P. and L. Bourbeau. 1985. TAUM-AVIATION: Its Technical Features and Some Experimental Results. Compuational Linguistics, 11: 18-27.

Jones, D. 1992. Non-hybrid example-based machine translation architectures. Proceedings of TMI-92. Montreall, 163-71.

Lelmann, H. and N. Ott. 1992. Translation relations ind the combination of analytical and statistical methesls in machine translation. Proceedings of TMI-92. Montreal. 237-48.

Maruyama, H. and H. Watanabe. 1992. Tree cover search algorithm for example-based Iranslation. Proceedings of TMI-92. Montreal. 173-84.

McLean, I. 1992. Example-based machine Iranstation using connectionist matching. Proceedings of TMI-92. Montreal. 35-43.

Nirenburg, S., J. Carbonell, M. Tomita and K. Goodmaın. 1992. Machine Translation: A Knowledge-Based Approach. San Mateo, CA: Morgan Kantimann.

Su, K-Y. and J-S. Chang. 1992. Why corpus-based statistics-oriented machine manslation. Prbeedlings of TMI-92. Montreal. 249-62.

Wilks, Y., Fitss, D., Guo, C-M., McDonald, J., Plate, T., de Slator, B. 1990. Providing Machine Tractable Dictionary Tools. Machine Thanslation, 5:2, 99-151. 